\title{
Análisis geográfico y potenciales medidas ambientales aplicables en el contexto del nuevo marco de la Red Natura 2000. Estudio de caso
}

\author{
Fernando GARCÍA QUIROGA \\ Gavitea Medio Ambiente. \\ nancht@hotmail.com \\ Jesús ABAD SORIA \\ Gavitea Medio Ambiente. \\ jababsaga@gmail.com
}

Recibido: 9 de julio de 2013

Enviado a evaluar: 17 de julio de 2013

Aceptado: 3 de octubre de 2013

\section{RESUMEN}

Los datos que proporciona en la actualidad Internet, mediante sus diferentes herramientas y páginas web que hacen posible el acceso a distinta información ambiental, junto al necesario trabajo de campo, permiten, que a través de exhaustivos inventarios puedan elaborarse medidas para mejorar las actuaciones a desarrollar en la Red Natura 2000. A través de la investigación llevada a cabo en un ámbito territorial dentro de dos LICs de la provincia de Ávila correspondiente a la cuadrícula 30T_UK_38, y considerando el nuevo Marco de Acciones Prioritarias de Financiación de la Red Natura 2000 presentado en el año 2013, se han enumerado aquellas que podrían aplicarse a dicho espacio concreto.

Palabras clave: Cuadrícula UTM, especies, Red Natura 2000, diversidad, propuestas de actuación, hábitats y marco geográfico.

\section{Geographical analysis and potential environmental measures applicable in the context of the new framework of Natura 2000. Case Study.}

\begin{abstract}
The data currently provided by internet, through its various tools and websites which allow access to different environmental information, along with the required field work, allow, that through exhaustive inventories measures could be elaborated to improve the actions to be developed in the Natura 2000 network. Through research carried out in a geographical area within two SCIs in the province of Avila corresponding to grid 30T UK 38, and considering the new Financing Priority Actions Framework of Natura 2000 Network, presented in 2013, there has been listed those that might apply to that specific space.
\end{abstract}

Key words: UTM gris, species, Natura 2000 Network, diversity, policy proposals, habitat, geographical framework. 
Analyse géographique et les mesures environnementales potentielles applicables dans le contexte du nouveau cadre de Natura 2000. Étude de cas.

\section{RÉSUMÉ}

Les données facilitées actuellement par le biais d'internet, à travers ses différents outils et pages Web qui rendent possible l'accès à l'information en matière d'environnement ainsi que le travail sur le terrain, permettent, à travers les inventaires exhaustifs, d'élaborer des mesures afin d'améliorer les actions à développer dans le réseau Natura 2000. Par le biais de la recherche effectuée dans un territoire comprenant deux sites d'intérêt communautaire (SIC) situé dans la province d'Ávila correspondant à la grille 30T UK 38 et tenant compte du nouveau Cadre d'Actions Prioritaires pour le Financement du réseau Natura 2000 présenté en 2013 , des actions ont été mentionnées pouvant être appliquées à cet espace spécifique.

Mots-clés: Grille UTM, espèces, réseau Natura 2000, diversité, propositions d'actions, habitats et cadre géographique.

\section{INTRODUCCIÓN}

En un mundo cada vez más tecnológico es posible obtener gran cantidad de información a golpe de un simple clik. Internet nos permite esto hoy en día, pero cuando se trata de un territorio concreto para poder obtener toda la información existente, y sobre todo cuando se trata de actualizarla, hay que recurrir para ello a una técnica más tradicional en el ámbito geográfico como es el trabajo de campo.

La necesidad de conocer el territorio para poder actuar en él es un requisito imprescindible si se pretenden implantar medidas adecuadas. La correcta planificación permite minimizar costes y a la vez mejorar la calidad de vida de los ciudadanos directamente o indirectamente, al hacer del entorno un lugar más saludable en el que vivir. Estas dos premisas deberían ser básicas en la sociedad actual y más aún, en el marco de crisis económica en el que se encuentran sobre todo los países del sur de Europa. El único "pero" que puede ponerse a estas necesidades, son es hecho que las actuaciones a desarrollar para la mejora a medio y largo plazo suponen un coste inicial, que muchas veces, no se está dispuesto a asumir por diferentes motivos.

Uno de los puntos en el que las propuestas de planificación y la ordenación del territorio se consideran básicos, es aquel que afecta a la Red Natura 2000. Para ello, se cuenta desde el año 2013 con un Marco de Acciones Prioritarias de Financiación de la Red Natura 2000, que deben ser el punto de partida para la mejora conjunta de la red y de los diferentes espacios que la componen. A pesar, de que las prioridades y medidas puedan ser aplicadas en su totalidad o parcialmente y de la mayor o menor idoneidad de las mismas, es necesario crear unas bases para poder actuar en esos espacios para mejorarlos siempre con dos premisas básicas, la conservación de los componentes ambientales y la mejora socioeconómica de las personas que habitan en estos lugares. 


\section{RED NATURA 2000 Y MARCO GEOGRÁFICO SELECCIONADO}

Parafraseando lo que señala el Ministerio Agricultura, Alimentación y Medio Ambiente en su página web ${ }^{1}$, Natura 2000 es una red ecológica europea de áreas de conservación de la biodiversidad. Consta de Zonas Especiales de Conservación designadas de acuerdo con la Directiva 92/43 CEE del Consejo, de 21 de mayo de 1992, relativa a la conservación de los hábitats naturales y de la fauna y flora silvestres, así como de Zonas de Especial Protección para las Aves establecidas en virtud de la Directiva Aves 79/409/CEE del Consejo, de 2 de abril de 1979, hoy reemplazada por la Directiva 2009/147/CE del Parlamento Europeo y del Consejo de 30 de noviembre de 2009.

Su finalidad es asegurar la supervivencia a largo plazo de las especies y los hábitats más amenazados de Europa, contribuyendo a detener la pérdida de biodiversidad ocasionada por el impacto adverso de las actividades humanas. Es el principal instrumento para la conservación de la naturaleza en la Unión Europea.

Considerando lo expuesto en las Directrices de Conservación de la Red Natura 2000, en España tenemos que las obligaciones jurídicas de conservación activa de los tipos de hábitat del Anexo I de la Directiva Hábitat y de las especies de los Anexos II de la Directiva Hábitat y I de la Directiva Aves y de otras especies de aves migratorias de presencia regular, han quedado plenamente incorporadas a nuestro ordenamiento jurídico por medio de la Ley 42/2007, de 13 de diciembre, del Patrimonio Natural y de la Biodiversidad.

Ante la oportunidad de acción que marca la Red Natura 2000, la necesidad de conservación de sus hábitats y especies, y la consideración de gran parte de la información disponible en materia ambiental, sobre todo aquella relacionada con el medio biótico se localiza en cuadrículas, se ha pretendido el análisis de una de ellas que se encuentre dentro de un espacio Red Natura 2000 y a ser posible que cumpla algunas de las consideraciones indicadas en el artículo 20 de la Ley 42/2007 que dice:

"Las Administraciones Públicas preverán, en su planificación ambiental o en los Planes de Ordenación de los Recursos Naturales, mecanismos para lograr la conectividad ecológica del territorio, estableciendo o restableciendo corredores, en particular entre los espacios protegidos Red Natura 2000 y entre aquellos espacios naturales de singular relevancia para la biodiversidad. Para ello se otorgará un papel prioritario a los cursos fluviales, las vías pecuarias, las áreas de montaña y otros elementos del territorio, lineales y continuos, o que actúan como puntos de enlace, con independencia de que tengan la condición de espacios naturales protegidos.

Las Administraciones Públicas promoverán unas directrices de conservación de las áreas de montaña que atiendan, como mínimo, a los valores paisajísticos, hídricos y ambientales de las mismas".

\footnotetext{
${ }^{1}$ http://www.magrama.gob.es/es/biodiversidad/temas/espaciosprotegidos/rednatura2000/vieja_default.aspx
} 
La cuadrícula UTM $(10 \times 10 \mathrm{~km})$ definida mediante el número del huso y la letra de la zona seleccionada es la 30T_UK_38, que cumple los requisitos estipulados de conectividad ecológica del territorio y área de montaña, al mejorar la coherencia ecológica, la funcionalidad y la conectividad de la Red Natura 2000. Forma parte del LIC ES4110034 Sierra de la Paramera y Serrota donde nacen algunos arroyos, perteneciendo uno de ellos al LIC ES4180081 Riberas del río Adaja y afluentes.

\section{REALIDAD ESPACIAL DEL TERRITORIO}

Se resume en los siguientes apartados en donde además de los datos existentes para esta cuadrícula en Internet, se añaden otros propios del trabajo de campo efectuado.

\section{1. ÁMBITO TERRITORIAL}

El ámbito territorial del estudio corresponde con la cuadrícula 30T_UK_38 y se encuadra en la parte occidental de la Sierra de la Paramera, englobando toda su vertiente norte y la zona más alta de la sur. Como núcleos de población presentes se encuentran Robledillo, Villaviciosa, La Hija de Dios, Narros del Puerto y Mengamuñoz donde comienzan las estribaciones orientales de La Serrota. En el caso de estos dos últimos municipios lindan en el extremo norte con la cuadrícula 30T_UK_39 y en el oeste con la 30T_UK_28. Al este se localiza la cuadrícula 30T_UK_48 y al sur la 30T_UK_37.

Figura 1. Marco geográfico del ámbito de estudio.

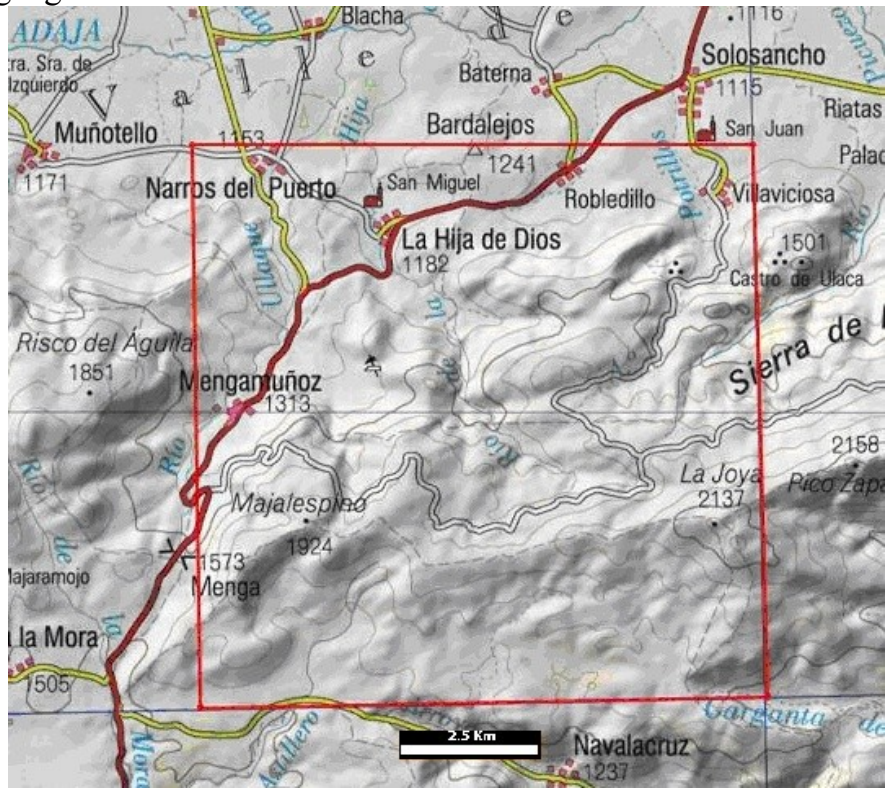

Fuente: SIG PAC modificado. 


\subsection{CLIMATOLOGÍA}

El espacio ocupado por la cuadrícula presenta una considerable variedad climática, consecuencia por un lado de la influencia atlántica que aportan los vientos ábregos del Suroeste, por otro del carácter continental y mediterráneo (aquí más continental) de la meseta castellana, y por último de la influencia de una serie de factores geográficos que también condicionan el clima de este espacio como serían la exposición, la topografía y la elevada altitud media consecuencia de la dominancia montañosa del entorno.

En cuanto a las precipitaciones, que rondan entre los 500 y los casi $1.000 \mathrm{~mm}$, se concentran entre octubre y mayo (periodo en el que parte de ellas son en forma de nieve) al bajar en latitud el frente polar, apareciendo en verano una marcada sequía (debida al casi constante posicionamiento del anticiclón en las azores) que solo se ve rota por tormentas originadas por nubosidad de desarrollo vertical. En el periodo de lluvias producidas por la afluencia sobre todo de borrascas procedentes del atlántico, tenemos en ocasiones, ciertas interrupciones en su llegada a consecuencia del posicionamiento, a veces duradero, del anticiclón continental que genera tiempo estable con posibilidad de frío intenso. Estas borrascas atlánticas llegan aquí algo debilitadas a consecuencia de que en primer lugar tienen que salvar la pantalla orográfica que supone la Sierra de Gredos, donde dejan el mayor volumen de precipitaciones, hecho este conocido como efecto Foehm.

Respecto a las temperaturas tenemos que la media anual supera ligeramente los $10^{\circ} \mathrm{C}$ en las partes más deprimidas, mientras en las zonas altas ronda los $5-6^{\circ} \mathrm{C}$, siendo enero el mes más frío y julio y agosto los más cálidos.

\subsection{EL RELIEVE: GEOLOGÍA Y GEOMORFOLOGÍA}

De norte a sur la cuadrícula viene determinada por la presencia marginal del Valle Amblés, fosa tectónica, cuyo amplio fondo de relieve llano situado a unos 1100-1150 $m$ está recubierto sedimentos terciarios. Desde este punto hacia el sur los relieves que lo enmarcan presentan una naturaleza principalmente granítica en su roquedo y el carácter de horst o bloques tectónicamente elevados.

Una segunda unidad es la que se da entre zonas más o menos deprimidas y las laderas de las sierras. Aquí se desarrollan superficies no muy inclinadas con pendiente $<8 \%$, que son los denominados glacis formados durante el Pleistoceno a expensas de la arenización de los granitos de las rocas de origen filoniano. Están formados por una cobertera de arenas y limos arcósicos con cantos dispersos.

Dejando atrás el pie de monte y las primeras alineaciones montañosas, previas, que rondan los 1500 - $1600 \mathrm{~m}$ aparece la Sierra de la Paramera en sí, con cumbres que superan claramente los $2000 \mathrm{~m}$ y en donde la acción del hielo y deshielo (periglaciarismo) es una constante. Dentro de las laderas de las sierras, las áreas con pendientes comprendidas entre el 8 y el $20 \%$ son las vertientes cubiertas por coluviones, que representan un conjunto heterogéneo de derrubios variados (bolos y clastos). Además 
en la Sierra de la Paramera la presencia de coluviones es habitual en las denominadas "navas" en las que se acumula el agua.

Cuando la pendiente se acentúa y ronda entre el 20 y el $40 \%$ tanto en la vertiente norte como en la sur aparecen pedreras y berrocales que se localizan por encima de los $1600 \mathrm{~m}$. Se asocian a afloramientos rocosos y están constituidos por bloques angulosos. Tanto las pedreras como los coluviones con importancia en los procesos gravitacionales constituyen espacios adecuados para la nidificación de diferentes aves rapaces.

A pesar de las culminaciones planas en los márgenes de la sierra que determinan formas en dorso de ballena (hecho que se da también en algunos espacios altos, próximos a las cimas), tenemos que en la zona de cumbres destaca la presencia de cabezas rocosas, caso de algunos de los picos situados hacia el este.

Además de estas consideraciones básicas del relieve, en el ámbito de esta cuadrícula no existen Puntos de Interés Geológico dentro del Inventario Nacional llevado a cabo por el Instituto Geológico Minero de España que sí existen en las cuadrículas situadas al este y oeste de la analizada.

\subsection{EDAFOLOGÍA}

Los suelos de la cuadrícula están constituidos por un dominio litológico fundamentalmente granítico y de relieve en conjunto bastante accidentado cuyos suelos conservan en su mayor parte un carácter natural, pues apenas han sido transformados en tierras de labor, aunque hayan sufrido los efectos de la antropización, debido a la apertura de pistas y a algunos incendios forestales para la búsqueda de nuevos pastos.

En términos generales, nos encontramos con el empardecimiento como el proceso edafogenético principal en suelos medianamente evolucionados y a la incorporación de materia orgánica ácida y poco humificada en los más incipientes. Esto significa que los suelos predominantes deben ser del grupo de los tradicionalmente llamados suelos pardos o tierras pardas, a los que aparecerán asociados en situaciones desfavorables litosuelos y ránkeres en condiciones de frío, erosión o fuerte presencia del roquedo en superficie o a muy escasa profundidad.

En líneas generales puede considerarse representativa la siguiente secuencia altitudinal catenal:

- En niveles inferiores de moderada o débil pluviosidad cuya vegetación potencial es principalmente encinares, suelos tipo tierra parda meridional, equivalentes a xerocrepts dístricos de la clasificación americana y cambisoles dístricos y húmicos de la FAO.

- En niveles medios de pluviosidad mas elevada correspondiente grosso modo al dominio de los melojares, las llamadas tierras pardas subhúmedas y húmedas, también conocidas como tierras pardas de melojar y tierras pardas centroeuropeas. Corresponden a xerumbrepts y/o haplumbrepts típicos o dístricos de la Soil Taxonomy a cambisoles húmicos en la clasificación de la FAO.

- En niveles superiores con bajas temperaturas y dominio de matorrales y pastizales, son los ránkeres y tierras pardas de césped alpino, junto con litosuelos 
en medios más o menos rocosos y suelos hidromorfos en depresiones, los suelos principales. En la clasificación americana y de la FAO corresponden principalmente a criumbrepts y criortents de la primera y leptosoles distritos de la segunda.

En relación con los niveles erosivos de los suelos, se observa que las mayores pérdidas de los mismos al año se localizan en las proximidades del puerto de Menga y del pico de la Joya o de la Serradilla, punto más alto de la cuadrícula, con unos valores de tipo medio que oscilan entre las $12-25$ T.ha/año, mientras en el resto las cifras se sitúan entre las $5-12$ T.ha/año o incluso inferiores.

\subsection{OROGRAFÍA E HIDROLOGÍA}

El espacio de estudio viene determinado por la abrupta topografía que supone la presencia de la Sierra de la Paramera, con unas pendientes que aumentan al acercarnos a sus cumbres y por el encajonamiento de algunos de sus arroyos. En el caso de la vertiente norte al ser predominante en la cuadrícula 30T_UK_38 su extremo más septentrional llega hasta la parte más meridional del Valle Amb̄lés dominada por la fosa que constituye el río Adaja, en donde desembocan todos los arroyos norteños de la cuadrícula pertenecientes a la cuenca del Duero, entre ellos el de los Poyales, Navaelvecino, la Vejiga, los Potrillos, la Garganta Honda, el Berrocal de la Duza, el de los Picos, los Arroyuelos, de la Meneagrande, del Medianero, de Majalespino o los ríos Ullaque y Picuezo. Mientras en la vertiente sur cuyas aguas van a parar al río Alberche se encuentran los arroyos de Becedillas, Pelacodillos, del Pastuelo, de Joyaldebro, de la Majadillafría, del Cimorro (que vierten al arroyo Chiquillo o de Navalacruz que pertenece al LIC Riberas del río Alberche y Afluentes), o los de Hoyuelos Chicos y Grandes que conforma el río Astillero, todos ellos concernientes a la cuenca del Tajo.

Todos estos cursos fluviales de aguas limpias y cristalinas, solo enturbiadas en ocasiones por las deyecciones del ganado, presentan un régimen pluvio-nival desde el noviembre a abril siendo pluvial en el resto del año. Presentan una marcada estacionalidad, si bien mantienen una pequeña lámina de agua incluso durante la época estival.

En cuanto a la presencia de elementos antrópicos destacan la presa existente en el arroyo de los Potrillos en las inmediaciones a Villaviciosa, aunque no presenta uso alguno, pues se encuentra parcialmente demolida al presentar dos agujeros en su dique de contención. Otros elementos presentes son pequeñas represas y conducciones, como las existentes en el arroyo de los arroyuelos que suministran agua al municipio de Solosancho.

Además de los elementos descritos aparecen otros de tipo natural como lagunas. En este caso la de Navas, situada en el límite noreste de la cuadrícula, trampales o tremedales que acumulan agua durante todo el año en varios puntos de la sierra, así como manantiales y fuentes como las existentes en el puerto de Menga o en la pista que parte a los pies de este y que comunica con el puerto de Navalmoral. 
En cuanto a la hidrología subterránea, la cuadrícula a pesar de la poca permeabilidad existente por la presencia del roquedo, pertenece en su extremo norte dentro de la zona más deprimida topográficamente, a la Unidad Hidrogeológica 02.21 Valle del Amblés, que presenta un acuífero tipo mixto del terciario-cuaternario, con el mismo volumen de entradas y salidas y con una potencial contaminación agrícola y ganadera por Abonos, Fitosanitarios, Fosfatos y Cloruros.

\subsection{ESPACIOS NATURALES PROTEGIDOS Y DE INTERÉS}

\subsubsection{RED NATURA 2000}

Los Lugares de Interés Comunitario (LICs) y las Zonas de Especial Protección para las Aves (ZEPAs) integran la Red Natura 2000 de la Unión Europea. Dichas zonas se fundamentan en la Directiva 92/43/CEE y en la Directiva 79/409 CEE, hoy reemplazada por la Directiva 2009/147/CE que contribuyen a garantizar la biodiversidad mediante la constitución de la Red Natura 2000, si bien en el caso de las segundas no están presentes en la cuadrícula analizada.

Los LICs son espacios delimitados para garantizar el mantenimiento o, en su caso, el restablecimiento, en un estado de conservación favorable, de lo tipos de hábitats naturales de interés comunitario y de las especies de interés comunitario, estando presentes en este ámbito territorial los siguientes:

- ES4110034 Sierra de la Paramera y Serrota. De las 22.663,15 has. de superficie que ocupa, aproximadamente una cuarta parte corresponde a la cuadrícula de análisis en la que las altitudes pertenecientes al LIC rondan entre los 1470 $\mathrm{m}$ y $\operatorname{los} 2134 \mathrm{~m}$. Como principales características recogidas en su ficha del LIC tenemos el presentar diversas formas de modelado, periglaciar, arrasamientos erosivos, encajamientos fluviales y alteraciones de las rocas, principalmente. En cuanto a su calidad e importancia viene determinada por la presencia de formaciones de matorral mediterráneo de interés, el gran valor de las comunidades de aves, especialmente de rapaces y paseriformes y por la existencia de una topografía de amplios contrastes lo que incrementa notablemente la diversidad y riqueza ecológica. Respecto a los factores de vulnerabilidad que pueden afectar en el futuro a este espacio son: la destrucción de la vegetación producida por incendios forestales (como el ocurrido en agosto de 2011 que calcino más de 700 has.); la pérdida de hábitats por los cambios en los usos ganaderos; y la instalación de infraestructuras de aprovechamiento eólico (que actualmente se está promoviendo en zonas no muy alejadas en este espacio, en concreto en la sierra de Ávila y junto al puerto de la Paramera). Otra amenaza considerable es la innecesaria concentración parcelaria de terrenos forestales, que genera destrucción de lindazos y establece una red de accesos difícilmente compatible con la conservación del lugar, a la que habría que sumar a partir de observaciones propias la apertura indiscriminada de pistas forestales para las forestaciones monoespecíficas de pino silvestre o albar 
(Pinus sylvestris) que han originado la pérdida de cervunales y el fraccionamiento de arroyos de cabecera y un aumento en el riesgo de incendios forestales por su inflamabilidad y por la presencia de ramas caídas en el suelo, aumentando el combustible. Las mejoras futuras del lugar pasan necesariamente a partir de lo recogido en la ficha del LIC por la repoblación forestal de grandes extensiones actualmente degradadas por la secular deforestación producida por quemas ganaderas reiteradas y sobrepastoreo, cosa que a nuestro parecer no es del todo aconsejable y solo en el caso de que parcialmente se plantasen especies caducifolias como el rebollo (Quercus pyrenaica) y no más pino albar, sobre todo si queremos conservar los Hábitats de Interés Comunitario presentes, que posteriormente serán enumerados y favorecer a especies como el corzo (Capreolus capreolus) que pueden minimizar con su presencia los conflictos ganaderos que produce el lobo (Canis lupus signatus), al ser escasas sus presas naturales.

Figura 2. Vista general del LIC ES4110034 Sierra de la Paramera y Serrota.

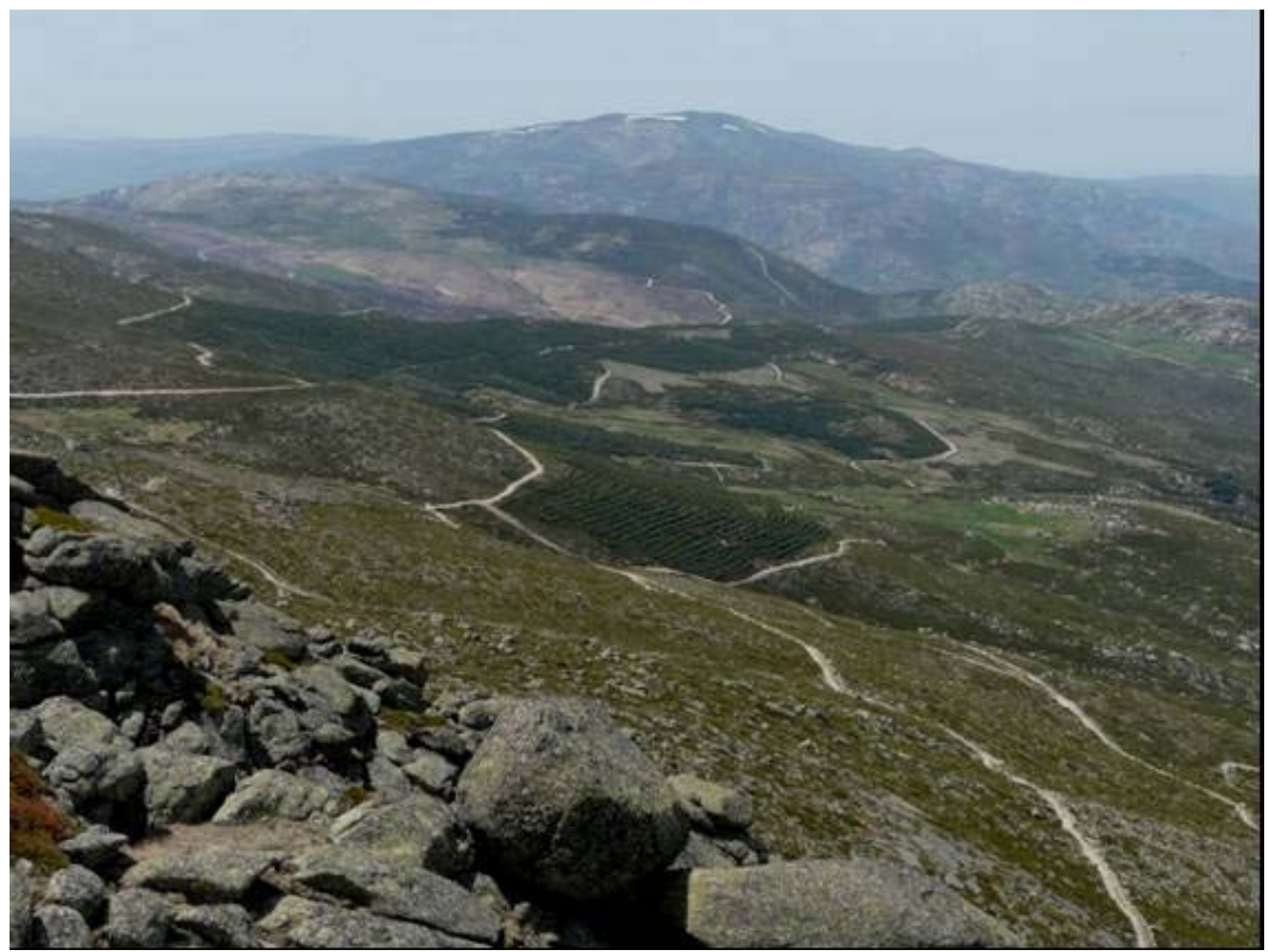

Fuente: Elaboración propia. 
- ES4180081 Riberas del río Adaja y afluentes. Su presencia en el ámbito de la cuadrícula 30T_UK_38 es relativamente testimonial y se circunscribe no al cauce principal, el río Adaja que queda cerca, y sí a uno de sus afluentes, en este caso al río Ullaque que ocupa una superficie desde su límite meridional hasta Narros del Puerto de unas 65 has. de las 1.390,68 totales del LIC. Éste río, a pesar de algunos residuos existentes y de vertidos de aguas residuales de origen urbano en uno de sus arroyos de cabecera como el que atraviesa la localidad de Mengamuñoz, muestra una elevada calidad de las aguas en el resto de sus tributarios y un más que aceptable estado de conservación en sus riberas, por la presencia continua de arbolado (principalmente sauces). Otra singularidad incluida en el LIC la constituyen los prados y zonas húmedas presentes en el punto donde se unen los arroyos que conforman el río.

Figura 3. Vista general del río Ullaque en el LIC ES4180081 Riberas del río Adaja y afluentes.

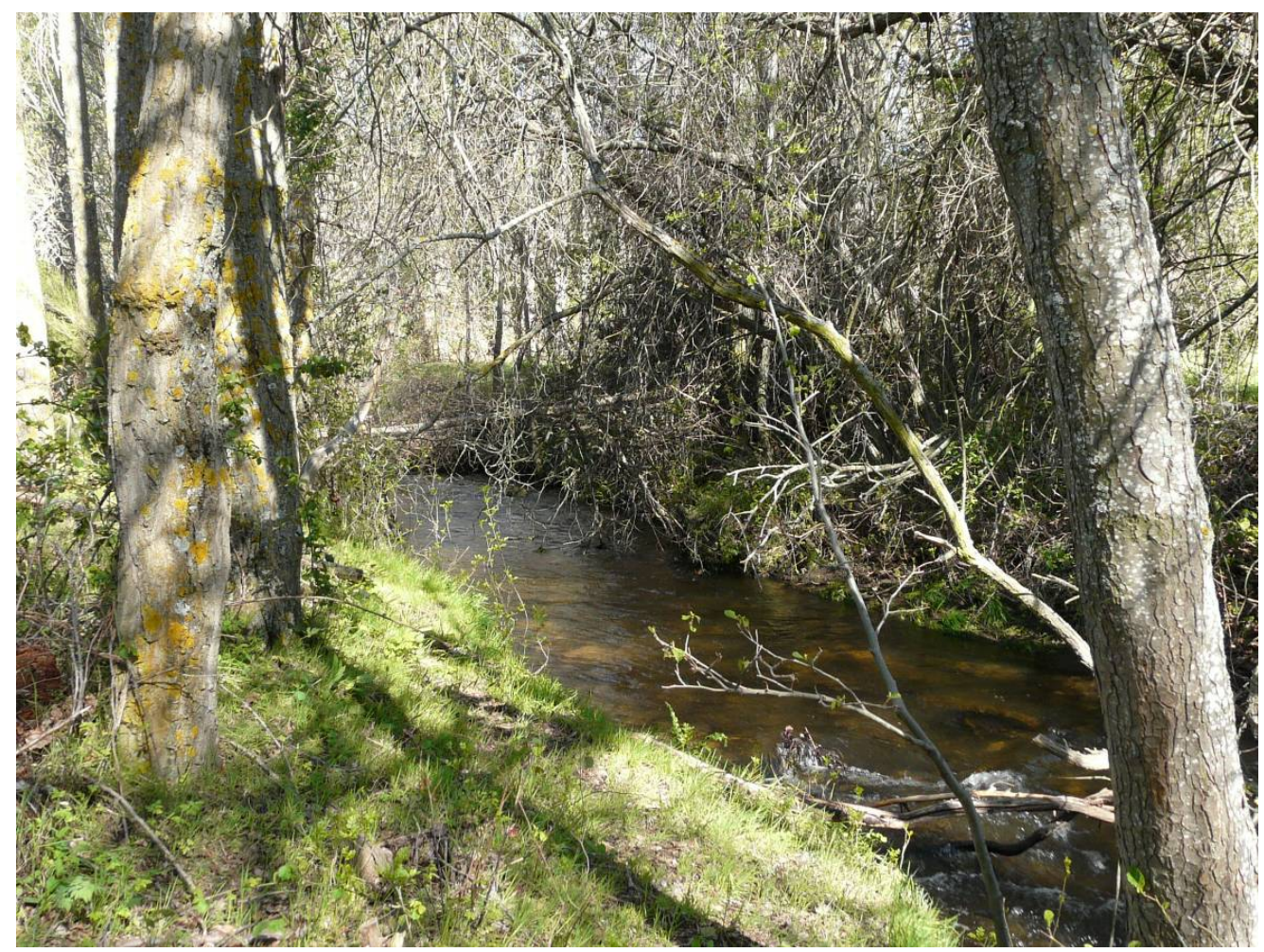

Fuente: Teresa Soria Martínez de Rituerto.

Además de estos dos LICs justo al sur de la cuadrícula en el linde de la misma con la 30T_UK_37, se encuentra el LIC ES4110078 Riberas del río Alberche y afluentes al que pertenece el arroyo de Navalacruz, que presenta un estado de conservación y 
una belleza excepcional y como mayor amenaza la reiteración de incendios forestales en la cabecera de la cuenca, que provocan deforestación y por tanto erosión y contaminación de las aguas superficiales, sedimentación y alteraciones en el cauce, y un régimen más irregular de lo debido.

Figura 4. LiCs de cuadrícula 30T_UK_38. El mayor corresponde a la Sierra de la Paramera y Serrota y el menor al de riberas del río Adaja y afluentes

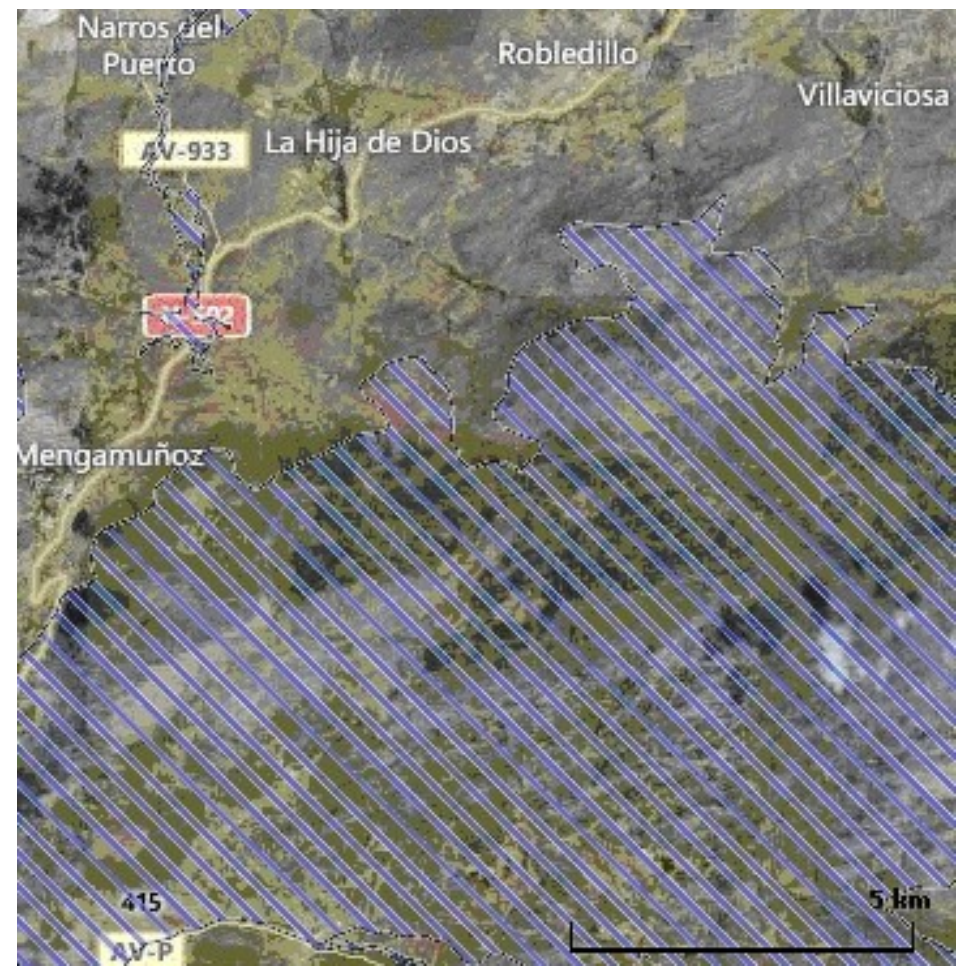

Fuente: Natura 2000 Viewer modificado.

\subsubsection{OTROS ESPACIOS NATURALES Y DE INTERÉS}

- Sierras de la Paramera y La Serrota. Abarca gran parte del ámbito territorial de la cuadrícula, a pesar de abarcar un ámbito mucho mayor (41.000 has). Están incluidas en el Plan de Espacios Naturales Protegidos de Castilla y León (Ley 8/1991, de Espacios Naturales de Castilla y León, aprobada por las Cortes de Castilla y León el 30 de abril de 1991). El Plan de Ordenación de los Recursos Naturales de este Espacio Natural se encuentra en proceso de tramitación. Los valores que justifican su declaración son similares a los del LIC destacando la acción de los hielos cuaternarios y la importante comunidad de aves, donde destacan los paseriformes y las rapaces. Todo ello confi- 
gura un paisaje dominado por una topografía variada con características de alta montaña, donde se combinan los terrenos ondulados y suaves, con los roquedos de fuertes pendientes. Las cotas más altas muestran los afloramientos rocosos que alternan con la vegetación de matorral de labiadas. Además existen praderas y pastizales que adquieren gran relevancia, destacando los cervunales, desarrollados en suelos profundos con hidromorfia temporal, donde es característica la presencia de Nardus stricta, sin olvidar el bercial de Stipa gigantea. Las formaciones arbóreas presentan escasa entidad, destacando las masas de melojo en las partes bajas junto a las encinas. En las márgenes de los ríos aparecen retazos del típico bosque galería a base de chopos, fresnos y sauces. Respecto a las masas de repoblación destacan los pinares silvestres, lo que denota que junto al pastoreo la vegetación que hoy se observa refleja el intenso uso a que se ha visto sometida.

- Monte de Utilidad Pública $n^{\circ}$ 47. Pertenece al municipio de Sotalvo y cubre una superficie bastante extensa (6.789 has.), de las que unas 3000, las más occidentales se incluyen en el ámbito de la cuadrícula llegando hasta el puerto de Menga. Presenta una amplia muestra de repoblaciones de pino silvestre de diversas edades y métodos que se combinan con pastos de altura de gran calidad y valor estratégico como estiviaderos, que proporcionan al monte unos elevados ingresos anuales (Gámez Montes, 2007).

- Áreas especialmente importantes para la herpetofauna española. En la cuadrícula se incluye una de las 12 áreas existentes en Castilla y León, la de las Sierras de la Paramera y La Serrota. Estas áreas determinan zonas, bajo distintos criterios, en las que se localizan especies de herpetofauna amenazada o elevado número de especies autóctonas, lo que supone un buen indicador de áreas de gran valor ecológico de interés para su conservación. En concreto se han encontrado en 41.000 has. analizadas (superando el ámbito territorial de la cuadrícula) 30 especies de las que 12 son endémicas.

\subsection{VEGETACIÓN ACTUAL Y HÁBITATS DE INTERÉS COMUNITARIO}

La vegetación actual de la cuadrícula, en sus partes bajas (cotas de 1200 a $1500 \mathrm{~m}$ ) del norte próximas al Valle Amblés se corresponde con bosquetes esclerófilos dominados por la encina (Quercus rotundifolia) presente en los Bardalejos y en laderas sur como la que mira al arroyo de los Picos. En ese mismo área, en concreto en zonas de la umbría de Robledillo y vertiente norte junto al arroyo de los Picos, en algunos puntos de los alrededores de Mengamuñoz y de manera aislada en la vertiente sur de la Paramera aparecen bosques marcescentes de rebollo (Quercus pyrenaica) que se distribuyen al igual que la encina por el piso supramediterráneo. Dentro de ese piso a unos $1600 \mathrm{~m}$ y limitando con el piso orotemplado por alcanzar hasta los $1900 \mathrm{~m}$ se han llevado a cabo por toda la vertiente norte de la Sierra de la Paramera amplias forestaciones con diversas variedades alóctonas de pino albar (Pinus sylvestris), donde su realización con apertura de enormes pistas forestales y métodos inapropiados, como terrazas y subsolados que no minimizan la erosión y la escorrentía superficial debido 
a la destrucción de la vegetación arbustiva y herbácea, desfiguran notablemente el bello paisaje, en el que existen, en algunos arroyos próximos al alto de La Hoya o de la Serradilla pequeños abedulares de Betula celtiberica, de gran valor ecológico.

En el resto de espacios del piso oromediterráneo de ambas vertientes se desarrollan las comunidades arbustivas de piorno serrano (Cytisus oromediterraneus) y enebro rastrero (Juniperus communis subsp. alpina), junto a pastizales siempreverdes y otras comunidades vegetales de montaña.

Como especie de especial relevancia por estar incluida en el Atlas y Libro Rojo de la Flora Vascular Amenazada de España en su adenda 2008 y en la base de datos del proyecto Pandora para el ámbito de la cuadrícula tenemos a Silene marizii Samp. catalogada como en peligro crítico (CR), por la Unión Internacional para la Conservación de la Naturaleza (UICN) o lo que es lo mismo, con riesgo extremadamente alto de extinción en estado silvestre en un futuro cercano. Ocupa taludes más o menos pedregosos y afloramientos rocosos en orientaciones de umbría, existiendo una población ubicada en el puerto de Menga (la segunda mayor de España), que presenta un estado de conservación bastante preocupante, en gran parte por las amenazas que sufre. Entre ellas pueden citarse la apertura de pistas forestales, la limpieza de taludes laterales de forma mecánica o utilizando herbicidas y la existencia de procesos de hibridación con Silene dioca. Como medidas para garantizar su supervivencia se propone su vallado, almacenamiento en bancos de germoplasma y el cultivo y micropropagación in vitro con el fin de realizar futuras reintroducciones (Pulgar \& Ortiz, 2009).

Para ampliar el conocimiento de las amplia variedad de especies vegetales existentes se recomienda la consulta de la base de datos del Sistema de la Vegetación Ibérica y Macaronésica para la cuadrícula de análisis, en las que además de conocer las asociaciones y subasociones presentes que a continuación enumeramos, también es posible conocer las especies presentes en cada una de ellas a partir de los inventarios realizados por Sánchez Mata, D (1989). De esta manera las asociaciones y/o subasociaciones presentes serían:

1. Arenario querioides-Festucetum summilusitanae subass. armerietosum caespitosae.

2. Arenario querioides-Festucetum summililusitanae subass. thymetosum zygidis.

3. Artemiso glutinosae-Santolinetum rosmarinifoliae.

4. Chenopodio vulvariae-Descurainietum sophiae.

5. Comunidad de Juncus bufonius y Sedum lagascae.

6. Cryptogrammo crispae-Dryopteridetum orealis subass.doronicetosum carpetanae.

7. Festuco amplae- Agrostietum castellanae.

8. Festuco amplae-Agrostietum castellanae subass. agrostietosum castellanae.

9. Festuco amplae-Agrostietum castellanae subass. caretosum verticillati.

10. Galio aparines-Conietum maculati subass. artemisietosum vulgaris.

11. Genisto cinerascentis- Cytisetum oromediterranei subass. stipetosum giganteae.

12. Genisto floridae-Cytisetum scoparii.

13. Glycerio declinatae-Apietum nodiflori.

14. Hieracio amplexicaulis-Saxifragetum orogredensis. 
15. Hyperico undulati-Juncetum acutiflori subass. juncetosum acutiflori.

16. Hyperico undulati-Juncetum acutiflori subass. menyanthetosum trifoliatae.

17. Linarietum niveae.

18. Polygono arenastri-Matricarietum matricarioidis.

19. Rhynchosinapi hispidae-Brassicetum barrelieri.

20. Sisymbrello asperae-Preslietum cervinae.

21. Sisymbrio afficinalis-Hordeetum murini.

22. Spergulario-Arnoseretum minimae.

23. Thymo-Plantaginetum radicatae.

24. Trifolio medii-Lathyretum nigri susass. physospermetosum cornubiensisis.

25. Urtico urentis-Malvetum neglectae.

Toda la diversidad vegetal existente (minimizada de manera injustificada por las masivas forestaciones de pinar), ha dado lugar a la presencia de un gran número de Hábitats de Interés Comunitarios (HICs) al amparo de los señalados en el Anexo I la Directiva 92/43/CEE y cuya presencia ha supuesto la necesidad de designar los LICs existentes. Entre ellos estarían:

- $\quad 3170$ Estanques temporales mediterráneos ${ }^{2}$.

- 3260 Ríos de pisos de planicie a montano con vegetación de Ranunculion fluitantis y de Callitricho-Batrachion.

- 4020 Brezales húmedos atlánticos de zonas templadas de Erica ciliaris y Erica tetralix ${ }^{3}$. Muy escaso.

- 4090 Brezales oromediterráneos endémicos con aliaga.

- 5120 Formaciones montanas de Cytisus purgans. Muy abundante.

- 6160 Prados ibéricos silíceos de Festuca indigesta. Relativamente abundante.

- 6220 Zonas subestépicas de gramíneas y anuales del Thero-Brachypodietea ${ }^{4}$. Relativamente abundante.

- 6230 Formaciones herbosas con Nardus, con numerosas especies, sobre sustratos silíceos de zonas montañosas (y de zonas submontañosas de la Europa continental) $)^{5}$. Algo abundante.

- 6420. Prados húmedos mediterráneos de hierbas altas del MolinionHoloschoenion.

- 6430 Megaforbios hidrófilos de las orlas de llanura y de los pisos montano y alpino. Más presentes en La Serrota que en el ámbito estricto de la cuadrícula.

- 6510 Prados pobres de siega de baja altitud (Alopecurus pratensis, Sanguisorba officinalis).

\footnotetext{
${ }^{2}$ HIC prioritario.

${ }^{3}$ HIC prioritario.

${ }^{4} \mathrm{HIC}$ prioritario.

${ }^{5}$ HIC prioritario.
} 
- 7140 "Mires" de transición.

- 8130 Desprendimientos mediterráneos occidentales y termófilos.

- 8220 Pendientes rocosas silíceas con vegetación casmofítica.

- 8230 Roquedos silíceos con vegetación pionera del Sedo-Scleranthion o del Sedo albi-Veronicion dillenii. Algo abundante.

- 91B0 Fresnedas termófilas de Fraxinus angustifolia. Escaso.

- 91E0 Bosques aluviales de Alnus glutinosa y Fraxinius excelsior (AlnoPadion, Alnion incanae, Salicion albae) ${ }^{6}$. Muy escaso y circunscrito al río Ullaque.

- 9230 Bosques galaico portugueses con Quercus robur y Quercus pyrenaica. Escaso.

- 92A0 Bosques galería se Salix alba y Populus alba.

- 9340 Bosques de Quercus ilex y Quercus rotundifolia. Escaso.

\subsection{FAUNA}

A partir de los datos ofrecidos por el Inventario Español del Patrimonio Natural y de la Biodiversidad y en concreto del Inventario Español de Especies Vertebradas Terrestres, en la cuadrícula 30T_UK_38 se localizan un total de 97 especies de las cuales 56 corresponden a aves, $2 \overline{7}$ a mamíferos, 7 reptiles y 6 anfibios y un pez continental. A pesar de lo señalado en este Inventario el número de aves nidificantes es mayor tal y como se puede deducir de los datos aportados en la ficha del LIC ES4110034 Sierra de la Paramera y Serrota y del trabajo de campo efectuado, señalándose aquí las especies incluidas en el Real Decreto 139/2011, de 4 de febrero, para el desarrollo del Listado de Especies Silvestres en Régimen de Protección Especial y del Catálogo Español de Especies Amenazadas. Entre ellas estarían como nidificantes la cigüeña blanca (Ciconia ciconia) presente en los núcleos de población como Robledillo, La Hija de Dios o Narros del Puerto, el milano negro (Milvus migrans), el gavilán (Accipiter nisus), el águila culebrera (Circaetus gallicus) visible en las inmediaciones del pico Gavilán, el cernícalo común (Falco tinnunculus), el autillo (Otus scops), el búho chico (Asio otus), la lechuza común (Tyto alba) el cárabo común (Strix aluco), la cogujada montesina (Galerida theklae), la oropéndola (Oriolus oriolus), el herrerillo capuchino (Parus cristatus), el martín pescador (Alcedo atthis), el mirlo acuático (Cinclus cinclus), el pechiazul (Luscinia svecica), el carbonero común (Parus major), la carraca (Coracias garrulus), el torcecuello (Jynx torquilla), el críalo europeo (Clamator glandarius), el trepador azul (Sitta europaea) o el buitre leonado (Gyps fulvus) que nidifica en las inmediaciones a la umbría de Robledillo mientras otras especies no nidificantes caso del buitre negro (Aegypius monachus) son bastantes frecuentes en el ámbito de la cuadrícula.

${ }^{6}$ HIC prioritario. 
Un hecho similar sucede con los mamíferos en donde se observa de la ausencia de numerosos quirópteros (todos ellos protegidos), además de otros que a pesar de no estar dentro del R.D 139/2011 por su relevancia y por haber sido avistados en el trabajo de campo son dignos de mención, caso la ardilla roja (Sciurus vulgaris), el corzo (Capreolus capreolus) o la cabra montés (Capra pyrenaica subsp. victoriae), si bien de esta última solo se han identificado excrementos.

En el caso de la herpetofauna además de la indicada en el Inventario Español, están identificados y protegidos en el R.D 139/2011, los tritones ibéricos (Lissotriton boscai) y jaspeado (Triturus marmoratus), el sapo de espuelas (Pelobates cultripes), el galápago leproso (Mauremys leprosa), la lagartija serrana (Iberolacerta monticola subsp. cyreni), la lagartija colilarga (Psammodromus algirus) y la culebras lisa meridional (Coronella girondica) y europea (Coronella austriaca).

Dentro de los peces están potencialmente presentes además del gobio (Gobio lozanoi), el calandino (Squalius alburnoides) y la bermejuela (Chondrostoma arcasii), si bien sólo esta última se encuentra incluida en el R. D 139/2011. Por último, en cuento a los invertebrados que pueden hacer uso de la cuadrícula y recogidos en la ficha del LIC y en el R.D 139/2011 destaca el ciervo volante (Lucanus cervus).

\subsection{PAISAJE}

Considerando el Atlas de los Paisajes de España y el Inventario Español del Patrimonio Natural y de la Biodiversidad y en concreto el Inventario Nacional de Paisajes, los dos paisajes existentes en la cuadrícula quedan recogidos en la siguiente tabla.

Tabla 1. Unidades Paisajísticas presentes.

\begin{tabular}{|c|c|c|c|c|}
\hline $\begin{array}{c}\text { Ámbito } \\
\text { territorial que } \\
\text { comprende }\end{array}$ & Unidad de paisaje & Subtipo de paisaje & Tipo de paisaje & Asociación \\
\hline $\begin{array}{c}\text { Áreas de menor } \\
\text { altitud }\end{array}$ & Valle de Amblés & Fosas abulenses & $\begin{array}{c}\text { Fosas del Sistema } \\
\text { Central y sus bordes }\end{array}$ & $\begin{array}{c}\text { Cuencas, hoyas } \\
\text { y depresiones }\end{array}$ \\
\hline $\begin{array}{c}\text { Zonas } \\
\text { superiores a los } \\
1400 \mathrm{~m}\end{array}$ & $\begin{array}{c}\text { Sierras de la } \\
\text { Paramera y La } \\
\text { Serrota }\end{array}$ & $\begin{array}{c}\text { Altas sierras } \\
\text { occidentales }\end{array}$ & $\begin{array}{c}\text { Macizos y sierras } \\
\text { altas del Sistema } \\
\text { Central }\end{array}$ & $\begin{array}{c}\text { Macizos } \\
\text { montañosos del } \\
\text { interior ibérico }\end{array}$ \\
\hline
\end{tabular}

Fuente: Inventario Nacional de Paisaje.

Aunque de manera igualmente resumida pero ampliando lo señalado anteriormente pueden señalarse los siguientes tipos y unidades del paisaje:

- Áreas más deprimidas próximas al Valle Amblés. Aquí es donde principalmente se localizan los usos agrícolas y núcleos de población, al igual que sucede con la mayoría de las infraestructuras como carreteras, caminos o tendidos eléctricos. Entre la vegetación existente destaca el matorral, el berceo y retazos de encinar. 
- Zona de piedemonte y primeras estribaciones montañosas. Esta marcada por una pendiente mayor que dificultó el arado de las tierras lo que ha supuesto que la actividad agrícola sea marginal, apareciendo ciertos usos ganaderos en áreas dominadas por la presencia de pastos y pastizales. El mosaico de paisajes es más variado, pues los lugares improductivos por la presencia de una topografía más abrupta y el afloramiento del roquedo (presencia de bolos y berrocales) y en los que se abandonó la agricultura y la ganadería han sido colonizados por el matorral, manteniendo en ocasiones algo de arbolado (principalmente algunas encinas y rebollos). Es destacable la presencia de algunos sotos.

- Zonas altas de la Sierra de la Paramera. Espacio dominado fundamentalmente por un mosaico compuesto por cabezas rocosas, piornales y enebrales, prados y cervunales y pinares de repoblación, entre los que descienden pequeños arroyos.

Estas unidades del paisaje junto a sus componentes principalmente, aquellos de tipo fisiográficos y de vegetación, determinan que la calidad paisajística de la cuadrícula pueda considerarse como de media a alta, siendo la predominante en líneas generales aquella catalogada como de media-alta.

\subsection{VIAS PECUARIAS Y PATRIMONIO HISTÓRICO}

Los usos ganaderos existentes en la cuadrícula 30T_UK_38 desde tiempos remotos han hecho posible que las vías pecuarias sean un elemento característico de este territorio. De esta manera pueden enumerarse:

- Cañada Real Leonesa Occidental que discurre en paralelo a la N-502 en el extremo occidental de la cuadrícula para posteriormente transitar entre los núcleos de población de La Hija de Dios y Narros del Puerto. La longitud total en el área de la cuadrícula asciende a unos $10 \mathrm{~km}$.

- Calzadilla o Cordel de Ávila. Discurre desde La Hija de Dios hasta Ávila capital, presentando un trazado bastante rectilíneo. Tan solo unos $3 \mathrm{~km}$ discurren por la cuadrícula.

- Cordel de Robledillo a la Laguna de Navas. Presenta una longitud de unos 4 km por el límite sur de la cuadrícula.

Respecto al Patrimonio Histórico, además de elementos como potros de herrar, tenadas, fraguas, cruces, molinos, lavaderos, hornos, sarcófagos, tumbas excavadas en la roca, paneras o fuentes públicas, $u$ otros de origen celta como los verracos, unos de ellos presente en el núcleo urbano de Villaviciosa, como elementos más representativos se encuentran los siguientes:

- Yacimiento visigodo de la Cabeza de Navasangil. Se ubica dentro del municipio de Solosancho, formando parte desde 1994 de la Zona Arqueológica de 
Ulaca (engloba el castro celta del mismo nombre, uno de los mayores de Europa occidental y situado a unos 600 del límite nororiental de la cuadrícula), y disfrutando de la categoría de Bien de Interés Cultural (BIC) desde 1986. La altitud del yacimiento y su orientación norte, hacen de este enclave un lugar inhóspito y estratégico, tanto por su dominio visual sobre gran parte del Valle Amblés, como por sus condiciones defensivas naturales: delimitado por pronunciadas pendientes graníticas, y emplazado en la confluencia del arroyo de Garganta Honda con el arroyo de los Potrillos.

- Castillo de Villaviciosa. Sus orígenes datan de finales del S.XIV, si bien no será hasta el S.XVI cuando finalice su construcción. Consta de planta rectangular con torre circular, matacanes y troneras de cerradura de ojo invertida. Esta declarado BIC y ha sido restaurado habiéndose convertido en hostal restaurante hasta hace unos años.

- Iglesia Nuestra Señora de la Asunción. Situada en Narros del Puerto, destaca por su estilo románico mudejar. Data del S.XIII, si bien fue modificada en el S. XVI.

- Ermita de San Miguel. Del S. XVIII, pertenece al término municipal de La Hija de Dios y se sitúa entre la Cañada Real Leonesa Occidental y el arroyo de los arroyuelos, presentando la típica arquitectura serrana de granito. Junto a esta ermita citar también la de San Juan, que aunque se sitúa fuera del ámbito de la cuadrícula, se encuentra a tan solo 400 del límite norte de la misma entre los núcleos de población de Solosancho y Villaviciosa.

\subsection{ELEMENTOS ANTRÓPICOS}

Se asocian principalmente a infraestructuras y a determinados usos del territorio, pudiéndose señalar los siguientes:

- Carretera N-502. Discurre por todo el margen occidental de la cuadrícula atravesando las poblaciones de Mengamuñoz, La Hija de Dios y Robledillo.

- Carreteras provinciales. Entre ellas se encuentran la AV-933 que parte de la N-502, hasta Narros del Puerto y después hasta la N-110, la AV-P-411 que une Solosancho con Villaviciosa y la AV-P-415 que une la N-502 con Navalacruz.

- Pistas forestales. Se localizan por toda la Sierra de la Paramera, estando ampliamente repartidas sobre todo por su vertiente norte.

- Depósitos de agua: Están presentes en Mengamuñoz y La Hija de Dios.

- Tendidos eléctricos. Existen dos principales que parten desde las coordenadas X: 331.466 e Y: 4.487.270, uno en dirección hacia Narros del Puerto y otro hacia La Hija de Dios y Solosancho (fuera ya del ámbito de la cuadrícula). Su potencia es de $45 \mathrm{kV}$. Además en el entorno del puerto de Menga existen varios que desde las antenas de telefonía descienden en dirección norte y otro que discurre próximo a la ermita de San Miguel. 
- Parques eólicos. No están presentes en la cuadrícula pero son visibles desde ella al estar situados al norte frente a la misma, concretamente en la Sierra de Ávila a distancias de unos 15-20 km. Desde este parque parte un tendido eléctrico de alta tensión igualmente visible por estar a unos 5-10 km.

- Antenas de telefonía móvil. Se localizan en el puerto de Menga donde hay 3 de ellas, en Mengamuñoz (1), en La Hija de Dios (1), cerca de Robledillo (2) y en Solosancho (2), si bien estas últimas se encuentran fuera del ámbito de la cuadrícula, pero son igualmente visibles, sobre todo una de ellas (la del ámbito de Las Chaparreras) que como algunas de las otras presenta alturas de 30 $\mathrm{m}$.

- Canteras. De pequeña extensión se encuentra actualmente fuera de uso y muy cercana al ámbito de los dos LICs existentes. Sus coordenadas se corresponden con X: 333.004 e Y: 4.486.015.

\subsection{POBLACIÓN Y MEDIO SOCIOECONÓMICO}

Incluiremos en este apartado además de los municipios presentes en la cuadrícula 30T_UK_38 (Mengamuñoz, Narros del Puerto y La Hija de Dios) al municipio de Solosancho, si bien solo los núcleos de población de Robledillo y Villaviciosa estarían incluidos, presentando en 2011195 y 124 habitantes respectivamente. En el caso de Navalacruz a pesar de que parte del término municipal se encuentra al sur de la cuadrícula, al no estar el núcleo de población en la misma se ha omitido su inserción en este apartado. En la siguiente tabla queda recogida la población de estos municipios.

Tabla 2. Número de habitantes (T: Total; H: Hombres; M: Mujeres) de los municipios de la cuadrícula.

\begin{tabular}{c|c|c|c|c|}
\hline Año & Mengamuñoz & Narros del Puerto & La Hija de Dios & Solosancho \\
\hline 2003 & T:69; H:32; M:37 & T:46; H:25; M:21 & T:91; H:50; M:41 & T:1043; H:546; M:497 \\
\hline 2004 & T:68; H:32; M:36 & T:44; H: 25; M:18 & T:94; H:50; M:41 & T:1032; H:540; M:492 \\
\hline 2005 & T:68; H:32; M:36 & T:43; H:23; M:20 & T:88; H:51; M:37 & T:1022; H:538; M:484 \\
\hline 2006 & T:66; H:32; M:34 & T: 37; H:19; M:18 & T:78; H:44; M:34 & T:1002; H:526; M:476 \\
\hline 2007 & T:67; H:32; M:35 & T:37; H:20; M:17 & T:79; H:44; M:35 & T:1006; H:527; M:479 \\
\hline 2008 & T: $67 ; H: 32 ;$ M:35 & T: 54; H:31; M:23 & T:74; H:42; M:32 & T:999; H:524; M:475 \\
\hline 2009 & T:67; H:32; M:35 & T:41; H:22; M:19 & T:81; H:47; M:34 & T:974; H:508; M:466 \\
\hline 2010 & T:66; H:30; M:36 & T:41; H:23; M:18 & T:75; H:42; M:33 & T:953; H:495: M:458 \\
\hline 2011 & T:67; H:31; M:36 & T:44; H:22; M:22 & T:77; M:41; M:36 & T:967; H:509; M:458 \\
\hline
\end{tabular}

Fuente: Datos Económicos y Sociales municipales de las Unidades Territoriales de España. Caja EspañaCaja Duero (Padrón municipal).

Se observa que todos los municipios presentan una escasa población no superando, excepto en Solosancho, ni siquiera los 100 habitantes, siendo mayor el número de hombres que de mujeres, excepto en Mengamuñoz.

En cuanto a la estructura productiva tanto en número de trabajadores como empresas por sector de actividad se señala en la siguiente tabla. 
Tabla 3. Número de trabajadores (T) y empresas (E) por sector de actividad en los municipios de la cuadrícula (diciembre de 2007).

\begin{tabular}{c|c|c|c|c|}
\hline Sector & Mengamuñoz & Narros del Puerto & La Hija de Dios & Solosancho \\
\hline Agricultura & T:6; E:1 & T:3; E:0 & T:4; E:0 & T:46; E:4 \\
\hline Industria & T:0; E:0 & T:0; E:0 & T:0; E:0 & T:3; E:0 \\
\hline Construcción & T:1; E:0 & T:1;E:0 & T:0; E:0 & T:71; E: 8 \\
\hline Servicios & T:7; E:2 & T:6; E: 1 & T:2; E: 1 & T:61; E: 9 \\
\hline No Consta & T:0; E:0 & T:0; E:0 & T:0; E:0 & T:0; E:0 \\
\hline Total & T:14; E:3 & T:10; E: 1 & T:6; E: 1 & T:181; E: 21 \\
\hline
\end{tabular}

Fuente: Datos Económicos y Sociales municipales de las Unidades Territoriales de España. Caja EspañaCaja Duero.

$\mathrm{Al}$ encontrarnos en un espacio eminentemente rural con algunos campos de cultivo y con pastos aptos para el ganado fundamentalmente vacuno y equino en gran medida extensivo, la presencia de trabajadores y empresas del sector primario es relativamente elevada, al igual que en la construcción, sobre todo en Solosancho, debido a la realización o rehabilitación de viviendas, muchas de ellas de segunda residencia. En cuanto al sector servicios su presencia se debe a las tiendas y establecimientos familiares existentes. Mientras la presencia de trabajadores en la industria es testimonial y sólo existen tres en Solosancho.

Otro componente socioeconómico importante viene constituido por la actividad comercial y turística, que se representa a continuación.

Tabla 4. Número de establecimientos comerciales y de turismo rural (año 2011).

\begin{tabular}{c|c|c|c|c|}
\hline Establecimientos comerciales & Mengamuñoz & Narros del Puerto & La Hija de Dios & Solosancho \\
\hline $\begin{array}{c}\text { Comercio al por mayor e } \\
\text { intermediarios }\end{array}$ & 0 & 0 & 0 & 4 \\
\hline $\begin{array}{c}\text { Comercio al por menor de } \\
\text { alimentación, bebidas y tabacos }\end{array}$ & 0 & 0 & 0 & 4 \\
\hline $\begin{array}{c}\text { Comercio al por menor de } \\
\text { productos no alimenticios }\end{array}$ & 0 & 0 & 0 & 4 \\
\hline $\begin{array}{c}\text { Comercio al por menor mixto y } \\
\text { otros }\end{array}$ & 1 & 0 & 0 & 3 \\
\hline Total & 1 & 0 & 0 & 15 \\
\hline Alojamientos de turismo rural & 2 & 1 & 0 & 19 \\
\hline
\end{tabular}

Fuente: Datos Económicos y Sociales municipales de las Unidades Territoriales de España. Caja EspañaCaja Duero y Sistema de Información Estadística. Dirección General de Estadística. Junta de Castilla y León.

Como es de esperar es en Solosancho donde más actividad comercial y turística se registra. Esto último, en términos generales en todos los municipios es debido a que el territorio presenta unos elevados atractivos patrimoniales tanto desde el punto de vista histórico como natural, si bien la oferta puede haberse sobredimensionado en los últimos años. 
A continuación se señalan los equipamientos sociales existentes en los municipios de la cuadrícula, que a pesar de la dispersión, cumplen una función básica, más aún si queremos evitar el despoblamiento del mundo rural o fomentar la llegada de nuevos habitantes.

Tabla 5. Número de equipamientos sociales (año 2011).

\begin{tabular}{c|c|c|c|c|}
\hline Tipo de equipamiento & Mengamuñoz & Narros del Puerto & La Hija de Dios & Solosancho \\
\hline Educativos (año 2011) & 0 & 0 & 0 & 2 \\
\hline Sanitarios (año 2011) & 1 & 1 & 1 & 4 \\
\hline )cio/Deportivos (año 2005) & 0 & 1 & 1 & 4 \\
\hline Total & 1 & 2 & 2 & 10 \\
\hline
\end{tabular}

Fuente: Datos Económicos y Sociales municipales de las Unidades Territoriales de España. Caja EspañaCaja Duero.

Tan solo el municipio de Solosancho presenta actualmente equipamientos educativos, mientras los de tipo sanitario están presentes en todos los núcleos de población existentes.

Por último, otro aspecto de interés lo constituye el número de viviendas y locales que quedan cuantificados en la siguiente tabla.

Tabla 6. Número de viviendas y locales.

\begin{tabular}{c|c|c|c|c|}
\hline Tipo & Mengamuñoz & Narros del Puerto & La Hija de Dios & Solosancho \\
\hline $\begin{array}{c}\text { Viviendas familiares } \\
\text { principales }\end{array}$ & 29 & 22 & 47 & 381 \\
\hline $\begin{array}{c}\text { Viviendas familiares no } \\
\text { principales secundarias }\end{array}$ & 43 & 150 & 97 & 33 \\
\hline $\begin{array}{c}\text { Viviendas familiares no } \\
\text { principales vacías u otro tipo }\end{array}$ & 2 & 10 & 13 & 139 \\
\hline Total & 74 & 182 & 157 & 553 \\
\hline Locales & 3 & 55 & 52 & 18 \\
\hline
\end{tabular}

Fuente: Instituto Nacional de estadística (INE). Censo de población y vivienda 2001.

El número de viviendas existente en estos municipios viene determinado por el volumen de población existente, por sus atractivos climáticos sobre todo los referentes a la época estival y por la relativa cercanía a una Comunidad Autónoma tan densamente poblada como Madrid. Teniendo en cuenta estos condicionantes destaca el número de viviendas familiares no principales secundarias. 


\section{POTENCIALES MEDIDAS APLICABLES DENTRO DEL NUEVO MARCO DE ACCIONES PRIORITARIAS DE FINANCIACIÓN DE LA RED NATURA 2000 EN EL ÁMBITO DE LA CUADRÍCULA}

La presencia de dos espacios Red Natura 2000 en el ámbito de la cuadrícula 30T_UK_38 y el lindar con un tercero, hacen que en este territorio una de sus prioridades desde el punto de vista medioambiental, lo constituya la aplicación de las medidas más adecuadas dentro del Marco de Acciones Prioritarias de Financiación de la Red Natura 2000, según lo establecido en el artículo 8 de la Directiva 92/42/CEE que han sido definidas en marzo de 2013 en el marco de la primera fase del proyecto Life+, para el periodo 2014-20207. Su aplicación viene determinada por la obligación jurídica que establece el artículo 45.1 de la Ley 42/2007, de 13 de diciembre, del Patrimonio Natural y de la Biodiversidad (redactado a partir del Real Decreto-Ley 17/2012, de 4 de mayo, de medidas urgentes en materia de medio ambiente), que dispone que respecto de las Zonas Especiales de Conservación y las Zonas de Especial Protección para las Aves, las Comunidades autónomas fijarán las medidas de conservación necesarias, que respondan a las exigencias ecológicas de los tipos de hábitats naturales y de las especies presentes en tales áreas, que implicarán adecuados planes o instrumentos de gestión específicos a los lugares, o integrados en otros planes de desarrollo que incluyan, al menos, los objetivos de conservación del lugar y las medidas apropiadas para mantener los espacios en un estado de conservación favorable. Estos planes deberán tener en especial consideración las necesidades de aquellos municipios incluidos en su totalidad o en un gran porcentaje de su territorio en estos lugares.

Antes de enumerar en la cuadrícula un resumen de las principales medidas a aplicar y a alcanzar y sus fuentes potenciales de financiación ${ }^{8}$ (sujetas actualmente a los drásticos recortes y restricciones presupuestarias que se están ejecutando en materia de medio ambiente) se enumeran las prioridades de conservación estratégicas para la Red Natura 2000 en España para el periodo 2014-2020 en las que se basan. Entre ellas se incluirían:

\subsection{PRIORIDADES GENERALES PARA NATURA 2000}

- Planificación (sexenal) para el mantenimiento o la restauración del Estado de Conservación favorable de los tipos de hábitat y las especies de interés comunitario para cada Región Biogeográfica, sus ZECs y ZEPAs.

\footnotetext{
${ }^{7} \mathrm{http} / /$ www.prioridadrednatura2000.es/wpcontent/uploads/2013/02/MARCOACCIONPRIORITARIA.pdf

${ }^{8}$ Fuentes de financiación: Fondeo Europeo Agrícola de Desarrollo Rural (FEADER), Fondo Europeo de Desarrollo Regional (FEDER), Fondo Social Europeo (FSE), Fondo Europeo Marítimo y de Pesca (FEMP), Instrumento Financiero para el Medio Ambiente (LIFE), Programa Marco de Investigación Horizonte 2020 (PMI).
} 
- Prevención de riesgos y amenazas y gestión preventiva para evitar el deterioro de los tipos de hábitat naturales y las especies de interés comunitario.

- Mejora de la conectividad e incremento de infraestructura verde mediante la restauración de espacios degradados.

- Mejora de medios para la vigilancia y gestión del territorio en Red Natura 2000.

\subsection{PRIORIDADES PARA LOS TIPOS DE HÁBITATS (AGRÍCOLAS Y FORESTALES) Y ESPECIES NATURA 2000}

- Mejora del conocimiento para evaluar el estado de conservación de los tipos de hábitat y especies de interés comunitario más desconocidos.

- Refuerzo de poblaciones de especies de interés comunitario y de aves del anexo I de la Directiva 2009/147/CE.

- Eliminación de riesgos y mejora de la conectividad ecológica y del éxito reproductor para las especies de interés comunitario, de las aves del anexo I de la Directiva 2009/147/CE, y de otras especies migratorias de aves cuya llegada sea regular.

- Fomento de los estudios científicos necesarios para alcanzar un estado favorable de conservación y mejorar la integridad y coherencia ecológica de la Red.

- Aprovechamiento sostenible de los recursos naturales y establecer medidas agroambientales, silvoambientales y otras medidas incluidas en Programas de Desarrollo Rural que contribuyan a la conservación de hábitats y especies.

- Restauración, mejora o mantenimiento de la naturalidad y complejidad estructural de los bosques de interés comunitario.

- Prevención y control de incendios y de la contaminación.

- Adquisición de la propiedad o derechos de uso de las masas de bosque con mayor valor ecológico y aumento de zonas húmedas en medio forestal.

- Adecuación de sendas e infraestructura para la interpretación.

\subsection{PRIORIDADES PARA LOS TIPOS DE HÁBITATS FLUVIALES, AZONALES (TURBERAS, ROQUEDOS) Y ESPECIES COMO EL LOBO}

- Directrices y planes específicos o sectoriales adaptados a las necesidades de conservación de tipos de hábitat y especies.

- Compensaciones por daños derivados de la presencia de fauna silvestre.

- Adquisición de la propiedad o derechos de uso de terrenos con suelos turbosos o cavidades o con presencia de espacios fluviales o zonas húmedas.

- Información pública, sensibilización y mejora de la calidad del agua.

- Realización de infraestructuras para la recuperación de hábitats y especies.

- Establecer medidas agroambientales y forestales y favorecer el conocimiento y sensibilización hacia las turberas, cuevas y otras especies o hábitats azonales. 
- Proyectos piloto para mejorar el estado general de los ecosistemas fluviales.

- Mejora de la conectividad ecológica e incremento de la infraestructura verde mediante la restauración de espacios degradados.

- Restauración del régimen hidrológico y caudales ecológicos.

- Control de plagas o especies sobreabundantes.

- Vigilancia sobre las presiones directas que afectan a la fauna silvestre y sobre los condicionados ambientales de los proyectos autorizados.

\subsection{OTRAS PRIORIDADES}

- Cooperación institucional para el desarrollo de la Red y su gestión eficiente.

- Participación de las comunidades locales en la gestión.

- Dotación de material informativo y equipamientos para la ordenación del acceso, la sensibilización, el uso, el conocimiento y el disfrute de lugares Natura 2000 .

- Promoción del turismo de naturaleza y de otras oportunidades de empleo.

- Adoptar nuevos mecanismos de financiación y adaptación al cambio climático.

\subsection{MEDIDAS PRIORITARIAS GENERALES PARA NATURA 2000}

- Establecer un programa de vigilancia y seguimiento que diagnostique las tendencias del estado de conservación adaptándose a las particularidades geográficas y ecológicas de los hábitats y especies. FEADER, FEDER, LIFE.

- Identificar y evaluar las presiones y amenazas a las que están sometidos los tipos de hábitat y especies presentes en la Red Natura 2000. FEADER, FEDER, LIFE.

- Establecer las medidas de conservación que eviten el deterioro de los tipos de hábitat y de las especies. FEADER

- Elaborar Planes Técnicos de Ordenación Cinegética. FEADER.

- Redactar planes de recuperación de especies amenazadas y de tipos de hábitat en peligro de desaparición. FEADER, FEDER, LIFE.

- Crear un Consejo Local consultivo para facilitar la participación ciudadana y la implicación de las partes interesadas en la gestión de las ZEC. FEDER, FSE.

- Proporcionar recursos para el mantenimiento de vehículos, edificios y material empleado en la vigilancia y gestión del territorio en Red Natura 2000. FEDER.

- Diseñar centros y programas de interpretación y atención al visitante acondicionándolos para visitantes discapacitados. FEDER.

- Dotar de los medios humanos y materiales necesarios para realizar programas de educación ambiental, y de concienciación de la población local. FEDER.

- Adoptar sistemas de retirada y tratamiento de los residuos sólidos existentes en las áreas de uso público, con recogida selectiva y el reciclaje. FEDER. 
- Contratar agentes medioambientales para seguimiento/vigilancia en los espacios de la Red Natura 2000 y el cumplimiento de la normativa medioambiental y promoción de su uso público de una forma sostenible, proporcionando asistencia e información a los usuarios del espacio. FSE, FEDER.

- Contratar trabajadores para ejecutar actuaciones de mejora medioambiental en los espacios de la Red Natura 2000. FEDER, FSE.

- Promover proyectos de adecuación y transformación de tendidos eléctricos para evitar la colisión o electrocución de las aves con los mismos. FEDER.

- Identificar áreas críticas y promover medidas para evitar la instalación de parques eólicos en áreas importantes para las especies sensibles. FEDER, LIFE.

- Crear y mantener un inventario georreferenciado de elementos naturales, culturales y geomorfológicos de valor para la fauna y flora silvestre de interés comunitario y establecer las medidas de prevención ante actuaciones que puedan afectarles negativamente. FEADER, FEDER, LIFE.

- Potenciar los estudios sobre el conocimiento de los diversos grupos faunísticos (vertebrados e invertebrados). PMI, LIFE.

- Realizar convenios de colaboración con universidades, centros públicos de investigación y sociedades científicas sin ánimo de lucro. FEADER, FEDER.

- Elaborar un estudio que cuantifique los beneficios derivados de la existencia de las ZEC teniendo en cuenta el valor económico total de su biodiversidad y de los servicios ambientales derivados. FSE.

- Aumentar los controles sobre el terreno para el cumplimiento de los condicionados ambientales, de las medidas compensatorias de los proyectos autorizados, y de las medidas de restauración acordadas en procedimientos sancionadores o de responsabilidad medioambiental. FEADER, FEDER.

- Incrementar la vigilancia sobre la caza o captura furtiva, el comercio ilegal de especies objetivo de fauna y sobre colonias de cría y nidos en época reproductora, así como sobre refugios, zonas de agregación invernal o premigratoria, dormideros o cualquier otro punto vital. FEDER, FSE.

- Elaborar materiales informativos generales sobre la Red Natura 2000 y específicos adaptados a los diferentes actores implicados como la población escolar presente en el ámbito local de las ZEC. FEADER, FEDER.

- Difundir los beneficios de las ZEC entre la opinión pública y, especialmente, entre las comunidades locales, para que puedan ser tomados en consideración en todos los procesos de toma de decisión y en los procedimientos de evaluación estratégica y de impacto ambiental. FEADER.

- Sensibilizar a las comunidades locales en áreas con poblaciones de grandes carnívoros sobre la viabilidad de la convivencia. FEADER.

- Desarrollar un programa de comunicación e información sobre las medidas de conservación, dirigidas a sectores sociales afectados o implicados. FEDER.

- Adquirir derechos de caza para la creación de zonas de refugio de caza en zonas de alto valor ecológico por la presencia de especies sensibles. LIFE. 
- Instalar paneles informativos en los puntos de acceso a las ZEC. Señalizar los accesos y caminos para regular el tráfico y los usos autorizados en colaboración con los municipios para la ordenación y gestión del Uso Público. FEADER.

- Desarrollar observatorios de aves para la práctica del "bird-watching". FEDER.

- Eliminar pistas y caminos sin utilidad evidente, restaurando la topografía y vegetación potencial. FEDER.

- Poner en marcha medidas para fomentar la conexión entre zonas que alberguen hábitats y poblaciones de especies afectados por fragmentación. FEADER.

- Favorecer la participación de propietarios de tierras y organizaciones locales en la conservación mediante programas de custodia del territorio. FEADER.

- Asesorar a los municipios sobre la adecuación de su normativa urbanística a los instrumentos de gestión y sobre su participación activa en su desarrollo. FSE.

\subsection{MEDIDAS PRIORITARIAS PARA LOS TIPOS DE HÁBITATS Y ESPECIES NATURA 2000 (AGRÍCOLAS Y FORESTALES)}

- Poner en marcha proyectos piloto de Contratos Territoriales en pastos montanos y creación de un Registro Ganadero en las ZEC. FEADER, FEDER.

- Realizar desbroces selectivos con perímetro irregular y en mosaico para mantener las superficies de pasto y matorral. FEADER, FEDER.

- Instalar barreras para evitar el paso del ganado en zonas donde se persiga la recuperación de ciertos tipos de hábitat y restaurar pastos en áreas erosionadas mediante cercado, siembras y plantaciones arbustivas. FEADER, FEDER.

- Reforzar el asesoramiento a los agricultores y ganaderos, más allá de la condicionalidad. Adopción y diseño de Códigos de Buenas Prácticas. FEADER.

- Inventariar y mantener en buen estado los puntos de agua, balsas o encharcamientos temporales presentes. FEADER, FEMP.

- Construir vivares de conejo, cercones, palomeras, y gestionar mosaicos para la mejora de poblaciones de perdiz y otras medidas que favorezcan a las presas de rapaces y mamíferos carnívoros amenazados. FEADER, LIFE.

- Eliminar o sustituir alambradas y cercados que sean impermeables a la libre circulación de la fauna silvestre. FEADER.

- Inventariar las construcciones agrarias de interés para la fauna. FEADER.

- Incorporar elementos constructivos que permitan la cría de aves en las naves agroganaderas de nueva construcción (huecos, tejas nido o cajas nido) y mantener con 'teja árabe' los corrales donde se detecte cría. FEADER.

- Mantener y restaurar setos en contacto con otros setos o bosquetes. FEADER.

- Dejar sin segar una banda de $1 \mathrm{~m}$. en los prados lindantes con setos, bosques o riberas, en áreas con anfibios amenazados, durante su dispersión. FEADER. 
- Adoptar compromisos para la reducción de fertilizantes y pesticidas. FEADER.

- Promover la apicultura, agricultura y ganadería ecológica. FEADER.

- Capturar, marcar y realizar radioseguimiento de especies amenazadas. FEADER.

- Realización de censos poblacionales bianuales de territorios de aves necrófagas, definiendo parámetros reproductores y disponibilidad de alimento. FEADER.

- Conocer las colonias de cría y lugares de paso de murciélagos. FEADER.

- Localizar y cartografiar las poblaciones de flora y fauna (invertebrados y anfibios) ligadas a pastos y matorrales y establecer criterios de manejo de los pastos y prados compatibles con su conservación. FEADER.

- Aumento de las patrullas de vigilancia contra incendios en las épocas de mayor frecuencia y diseñar infraestructuras contra ellos teniendo en cuenta los requerimientos de especies y hábitats de interés comunitario. FEADER, FEDER.

- Editar materiales de formación para gestores de cotos, agricultores y ganaderos relativos a métodos respetuosos con los hábitats y especies silvestres. FEADER.

- Construir en explotaciones ganaderas en estabulación semipermanente, tanques de almacenamiento o fosas, estercoleros y bolsas impermeabilizadas natural o artificialmente, estancos y con capacidad adecuada para la retirada de los estiércoles y/o purines de la explotación. FEADER, FEDER.

- Realizar infraestructuras ganaderas (Ej. corralizas, abrevaderos y cercados) para favorecer el aprovechamiento ganadero compatible con la conservación de los tipos de hábitat de interés de pastizal y matorral. FEADER, FEDER.

- Elaborar Planes especiales que contengan especificaciones sobre las mejores prácticas selvícolas, los aprovechamientos forestales y la planificación de tratamientos fitosanitarios para prevenir y controlar la presencia de plagas y enfermedades en las masas forestales de la Red Natura 2000. FEADER

- Redactar y ejecutar proyectos para transformar los bosques de repoblación de coníferas en masas mixtas irregulares que aumenten la biodiversidad, y para mejorar la integración de las pistas, reduciendo su impacto. FEADER, FEDER.

- Estimar y retirar la madera muerta del pinar y restaurar bosquetes (robledales) en parcelas que se encuentren lindando o entre manchas preexistentes. FEADER.

- Recuperar setos para mejorar la conectividad entre los robledales mediante plantación de especies autóctonas, con origen certificado. FEADER.

- Mantener en los bosques al menos 30 árboles por ha. aptos para la nidificación (considerando diámetro, agujeros, etc.). Fuente de financiación no definida.

- Colocar refugios artificiales para especies forestales dependientes de oquedades e implantar pequeños bosquetes de borde de pastizal. FEADER 
- Controlar las visitas y actividades (escalada, acampada libre, parapente, batidas cinegéticas, circulación de motos, quads y todoterrenos, etc.) sobre todo en áreas críticas durante las épocas de mayor vulnerabilidad (reproducción y crianza de pollos) restringiendo el paso a las zonas más sensibles. FEDER, FEADER, FSE.

- Monitorizar bianualmente la ocupación por quirópteros forestales de las cajas nido y otros refugios artificiales instalados en el bosque. FEADER.

- Seleccionar parcelas de 1 hectárea para medir cada 5 años la evolución del estado de conservación de los bosques esclerófilos bajo condiciones controladas y en particular con y sin intervención del ganado. FEADER.

- Realizar censos poblacionales periódicos de aves forestales. FEADER.

- Analizar el impacto de los incendios sobre los bosques naturales y sobre las plantaciones forestales y redactar directrices de lucha contra incendios. FEDER

- Realizar campañas de sensibilización dirigidas a colectivos específicos con incidencia en los riesgos de incendios, por ejemplo a los agricultores y ganaderos para el abandono de la quema de matorrales y rastrojeras, a los excursionistas sobre el riego de las barbacoas, etc. LIFE.

- Regular el uso de rodenticidas en campo abierto y desarrollar planes de vigilancia y alerta para combatir las plagas de micromamíferos. FEADER

- Reducir el uso de insecticidas y fitosanitarios en masas arboladas. Prohibir de forma específica la fumigación desde avioneta durante el periodo reproductor en las áreas de nidificación de especies. FEADER, FEDER.

- Editar materiales de formación relativos a métodos de silvicultura respetuosos con los tipos de hábitat naturales y las especies silvestres. FEADER, FEDER.

- Impulsar actividades de educación ambiental y formación, que favorezcan un cambio de actitud frente a los insectos forestales. FEADER, FEDER, FSE.

- Elaboración de material divulgativo sobre la importancia de los quirópteros forestales, pícidos, invertebrados xilófagos, tejos y de otras especies secundarias en los bosques, así como de formaciones forestales como enebrales. FEADER.

- Adquisición de la propiedad o derechos de uso de las masas de bosque con mayor valor ecológico/hidrológico. LIFE

- Crear senderos y zonas de observación de hábitats y especies forestales. FEDER.

\subsection{MEDIDAS PRIORITARIAS PARA LOS TIPOS DE HÁBITATS FLUVIALES}

- Realizar proyectos para restaurar y conservar hábitats fluviales. FEDER, LIFE.

- Redactar directrices para la pesca continental y campañas de información a la sociedad en general en zonas de red Natura 2000, orientadas a conservar las especies autóctonas y a eliminar las especies exóticas. FEDER, FEMP. 
- Elaborar anualmente un informe específico en el que se establecerá el estado ecológico, las posibles fuentes de contaminación y alteración del hábitat, así como las medidas necesarias para garantizar el buen estado ecológico. FEDER.

- Establecer el caudal ambiental del río y realizar un seguimiento específico del funcionamiento de los sistemas de depuración existentes en los núcleos de población que vierten a las ZEC y de otras actividades industriales. FEDER.

- Ejecutar los planes de saneamiento y depuración pendientes de los núcleos que vierten a los ríos de las ZEC o drenan hacia sus zonas húmedas. FEDER.

- Identificar y corregir los vertidos y el depósito de sustancias y compuestos (purines, insecticidas, plaguicidas, etc.). FEDER.

- Realizar sueltas de especies piscícolas autóctonas genéticamente controladas en tramos seleccionados donde se den condiciones de hábitat adecuadas. LIFE.

- Identificar y eliminar posibles puntos de mortalidad (puntos negros) para anfibios y reptiles de interés comunitario. FEDER.

- Realizar la instalación y el mantenimiento y limpieza de las escalas piscícolas y dispositivos instalados para garantizar su funcionalidad en todo momento y, de esta forma, facilitar los desplazamientos de los organismos acuáticos. FEDER.

- Establecer acuerdos voluntarios para mantener sin cultivar una banda de al menos 10 metros a cada lado del cauce fluvial. FEADER.

- Realizar prospecciones, transeptos y censos para evaluar el estado de conservación y las poblaciones de flora y fauna. FEADER, FEMP.

- Difundir la normativa de uso público en ecosistemas fluviales. FEADER.

- Elaborar material divulgativo sobre el valor de los bosques riparios. FEADER.

- Divulgar información en el sector piscícola y forestal, con la finalidad de favorecer la aceptación de los mamíferos semiacuáticos. FEADER.

- Instalar cercados para evitar la entrada del ganado y construir abrevaderos para evitar que el ganado abreve en cauces y zonas encharcadas. FEADER, FEDER.

\subsection{MEDIDAS PRIORITARIAS PARA LOS TIPOS DE HÁBITATS AZONALES (TURBERAS, ROQUEDOS) Y ESPECIES COMO EL LOBO}

- Redactar directrices para conservar quirópteros cavernícolas. FEDER, LIFE.

- Eliminar periódicamente las plantas leñosas dentro del perímetro de protección de las turberas y brezales húmedos. Fuente de financiación no definida.

- Reducir el nivel trófico en turberas y restablecer su función filtradora para mejorar su renaturalización química. Fuente de financiación no definida.

- Velar por el mantenimiento de los nidos de hirundínidos. FEADER. 
- Instalar sobre el terreno, en las zonas más vulnerables de turberas y roquedos, paneles que además de las normas para su protección, expliquen los valores del hábitat o especie y la gestión para su conservación. FEADER, FEDER.

- Definir perímetros de protección para cada turbera teniendo en cuenta la dirección de los flujos de escorrentía superficial y drenajes naturales. FEADER.

- Controlar las actuaciones que produzcan drenajes, captaciones o que impidan la llegada de agua tanto a los sistemas superficiales como acuáticos. FEADER.

- Vigilar, informar y controlar accesos a personas y vehículos a zonas sensibles en periodos críticos y eliminar las vías de escalada próximas a nidos. FEADER.

- Controlar la recolección de plantas medicinales presentes en los tipos de hábitat. Fuente de financiación no definida.

- Monitorizar la incorporación de buitres leonados subadultos a la población reproductora. LIFE, PMI.

- Prevenir el uso y eliminar lazos, cepos y veneno. FEDER, FEADER, LIFE.

- Controlar los perros de caza, limitar el uso de munición de plomo y vigilar y penalizar el uso ilegal de métodos de control de predadores. FEADER, FEDER.

- Fomentar medidas disuasorias (Ej. Cerramientos con pastores eléctricos, perros) para evitar daños a ganaderos y apicultores e indemnizar a los mismos por los daños provocados por ataques de fauna silvestre. FEADER, FEDER.

- Apuntalamiento y estabilización de infraestructuras en desuso que actúan de refugio de quirópteros cavernícolas. FEDER

- Reducir los fertilizantes y fitosanitarios cerca de las turberas. FEADER.

- Establecer ayudas o deducciones económicas a los propietarios que mantengan colonias de quirópteros en sus edificios o infraestructuras. FEADER.

- Mantener una carga ganadera entre 0,037 y $1 \mathrm{UGM} / \mathrm{Ha} /$ año dentro del perímetro de protección de las turberas. FEADER.

- Cartografiar y mejorar los inventarios de turberas, tobas, roquedos, cuevas y otros tipos de hábitat de interés comunitario de superficies reducidas, definiendo criterios cuantitativos para establecer el estado de conservación. FEADER

- Estudios climáticos e hidrológicos sobre la situación real y la variación de la capa freática en la turbera. PMI.

- Realización de censos poblacionales anuales de rapaces rupícolas y quirópteros cavernícolas, definiendo sus parámetros reproductores. FEADER.

- Estudiar la dinámica geomorfológica de los tipos de hábitat rocosos. FEADER

- Determinar los niveles de biocidas y otros contaminantes en huevos, y su influencia en el éxito reproductor y la mortalidad. FEADER, PMI.

- Adquirir la propiedad o derechos de uso restringido de terrenos dentro del perímetro de protección de las turberas. LIFE. 
- Instalar abrevaderos y cercar áreas higroturbosas donde se ha identificado rodadas o un pisoteo excesivo. FEADER, FEDER.

- Instalar y mantener Puntos de Alimentación Suplementaria para aves necrófagas y evaluar el uso realizado del mismo por estas especies. FEADER.

- Crear Centros de Recuperación de Fauna Silvestre y llevar a cabo un control fisiológico y toxicológico de los ejemplares que ingresen en ellos, así como de puestas no exitosas o pollos muertos. FEDER.

\subsection{OTRAS MEDIDAS PRIORITARIAS}

4.9.1. PARA ASEGURAR LOS BENEFICIOS ECOSISTÉMICOS, ESPECIALMENTE EN RELACIÓN CON LA MITIGACIÓN Y LA ADAPTACIÓN AL CAMBIO CLIMÁTICO

- Evaluar y cartografiar la vulnerabilidad al cambio climático de los tipos de hábitat y taxones españoles clave (acuáticos, alta montaña, etc.). LIFE, PMI.

- Consolidar redes de seguimiento ecológico a largo plazo e integración de los datos para detectar los efectos del cambio climático sobre tipos de hábitat y especies de interés comunitario. FEDER, LIFE.

- Identificar un sistema de indicadores biológicos de los impactos del cambio climático, y definición de protocolos de medida que conformen un sistema de vigilancia y alerta temprana. LIFE, PMI

\subsubsection{PARA PROMOVER EL TURISMO Y EL EMPLEO SOSTENIBLES.}

- Crear un servicio de asesoramiento sobre buenas prácticas y oportunidades económicas y sociales (empleos verdes). FEADER, FEDER, FSE.

- Elaborar materiales de promoción turística. FEADER, FEDER.

- Determinar la capacidad de acogida de visitantes o el límite de cambio aceptable de las zonas más sensibles de las ZEC. FEDER.

- Formar a guías turísticos locales y empresas de deporte en la naturaleza para el desarrollo respetuoso de su actividad y para que colaboren con la sensibilización hacia el patrimonio natural de sus clientes. FSE, FEADER, FEMP, FEDER.

- Promover la implantación de la Carta Europea de turismo sostenible. FEDER.

- Apoyar la puesta en marcha de establecimientos de comercialización local de productos etiquetados y certificados, con venta complementaria online. FEDER.

- Asistir a ferias y eventos internacionales para promocionar los productos artesanales respetuosos con la biodiversidad y el turismo de naturaleza. FEDER. 


\subsubsection{PARA PROMOVER ENFOQUES INNOVADORES EN LA RED NATURA 2000}

- Definir un sistema de pago por servicios ambientales de apoyo a los planes de gestión sostenible que incentive las externalidades sociales y ambientales que generen las explotaciones agrarias. FEADER.

- Valorar la puesta en marcha de un sistema de subastas y créditos de biodiversidad como alternativa al sistema de pagos homogéneos por ha. para la reversión a bosques, el mantenimiento de prados de siega y de setos. FEADER.

- Realizar una propuesta de Reforma Fiscal que tenga en consideración las necesidades de protección y financiación de la Red Natura 2000. FEADER.

- Definir la estructura de un Fondo específico para la Conservación del Patrimonio Natural que incluya la conservación de la Red Natura 2000. FEADER.

\section{CONCLUSIONES}

En un mundo cada vez más globalizado se ha ido instaurando la noción equivocada de que existen territorios vacíos, improductivos en lo económico o que simplemente son socialmente vaciables, con el fin de que ciertos actores interesados puedan controlar los bienes naturales existentes en esos espacios. Esto se produce cuando el territorio carece de artefactos u objetos valiosos que pueden ser "sacrificables" dentro de la lógica del capital (Sack, 1986). La visión miope de estas políticas aplicadas a espacios geográficos caracterizados por su relativo aislamiento y la escasa densidad poblacional hacen que puedan desarrollarse e instalarse discursos aptos para la aparición de nuevos emprendimientos productivos excluyentes. De esta manera, al mismo tiempo se constituye el punto de partida para la conformación de otros "lenguajes de valoración" en torno al territorio, por parte de las comunidades afectadas (Svampa, 2009).

Ante esta situación la presencia de espacios Red Natura 2.000 debe convertir a los territorios como el de la cuadrícula 30T_UK_38 en lugares con oportunidades de lograr el tan ansiado desarrollo sostenible. Para ello, la aplicación de medidas como las propuestas en el marco de acción prioritaria en Red Natura 2.000, que han sido resumidas y adaptadas a la realidad espacial del marco territorial analizado (hábitats y especies agrícolas, forestales, fluviales y azonales), deben servir de ejemplo de cómo es posible encontrar una armonía entre ser humano, mejoras socioeconómicas y conservación de la biodiversidad. 


\section{BIBLIOGRAFÍA}

BAÑARES, Á., G. BLANCA, J. GÜEMES, J.C. MORENO \& S. ORTIZ, eds. (2009). Atlas y Libro Rojo de la Flora Vascular Amenazada de España. Adenda 2008. Dirección General de Medio Natural y Política Forestal (Ministerio de Medio Ambiente, y Medio Rural y Marino)-Sociedad Española de Biología de la Conservación de Plantas. Madrid, 155 pp. (I. PULGAR y S. ORTIZ. Silene marizii Samp. pp58-59.)

BARTOLOMÉ, C, ÁlVAREZ JIMÉNEZ, J, VAQUERO, J, COSTA, M, CASERMEIRO, M, GIRALDO, J \& ZAMORA J (2005). Los Tipos de Hábitats de Interés Comunitario de España. Guía Básica. Ministerio de Medio Ambiente.

CORRALES BERMEJO, L. (coord.). (2002): Recursos Naturales de las Sierras de Gredos. Institución "Gran Duque de Alba". Excelentísima Diputación provincial de Ávila.

FERNÁNDEZ, J. (2000). Avance del Atlas de Quirópteros de Castilla y León. Junta de Castilla y León. Consejería de Medio Ambiente. Informe inédito.

GIL SÁNCHEZ, L \& TORRE ANTÓN, M (ED) 2007. Atlas forestal de Castilla y León. Junta de Castilla y León. Consejería de Medio Ambiente. Valladolid. Tomo II. Futuro de los bosques. Montes emblemáticos de Castilla y León (Jesús Gámez Montes). pp 725- 748.

GONZÁLEZ DEL TÁNAGO, M. et al. 1992. Estudio de las riberas de los principales ríos de la Cuenca del Duero. Bases para su gestión y conservación. Junta de Castilla y León. Dirección General del Medio Natural. Consejería de Medio Ambiente y Ordenación del Territorio. (Informe inédito, 405pp).

GUIL, F \& MORENO-OPO, R, (Coords), (2007). Catálogo de buenas prácticas para la gestión del hábitat en Red Natura 2000: bosque y matorral mediterráneos. Una propuesta de actuaciones financiables en Red Natura. Fundación CBD-Hábitat. Madrid.

JUNTA DE CASTILLA Y LEÓN (2013). Sierra de la Paramera y La Serrota. http://www.jcyl.es/web/jcyl/MedioAmbiente/es/Plantilla100/1131977582167/__/ [Consultado el 20-04-2013].

JUNTTA DE CASTILLA Y LEÓN (2013). Sistema de Información Estadística. http://www.jcyl.es/sie/ [Consultado el 15-04-2013].

LÓPEZ GONZÁLEZ, F. J.; LIZANA AVIA, M; SILLEROS PABLOS, N. Y PÉREZ MELLADO, V. (2000). Primer Informe del Convenio entre la Asociación Herpetológica Española y la Junta de Castilla y León (Inédito).

MARTII, R. \& J. C. DEL MORAL (eds.) (2003). Atlas de las aves reproductoras de España, DGCN-SEO/BirdLife, Madrid.

MATA OLMO, R. y SANZ HERRÁIZ, C. (Dir.) (2003). Atlas de los paisajes de España. Madrid. Ministerio de Medio Ambiente. Centro de Publicaciones.

NOTICIAS JURÍDICAS (2013). Legislación. Ley 42/2007, de 13 de diciembre, del Patrimonio Natural y de la Biodiversidad. http://noticias.juridicas.com/base_datos/Admin/142-2007.html [Consultado el 2804-2013]. 
PALOMO L. J, GISBERT, J \& BLANCO, J. C (2007) EDITORES. Atlas y Libro Rojo de los mamíferos terrestres de España. Ministerio de Medio Ambiente. Dirección General para la Biodiversidad, Sociedad Española para la Conservación y Estudio de los Murciélagos (SECEMU) y Sociedad Española para la Conservación y Estudio de los Mamíferos (SECEM).

PLEGUEZUELOS, JUAN M., MÁRQUEZ, R \& LIZANA, M (2002). Atlas y Libro Rojo de los anfibios y reptiles de España. Ministerio de Medio Ambiente.

SÁNCHEZ-MATA, D. (1989): Flora y vegetación del Macizo oriental de la Sierra de Gredos. Institución Gran Duque de Alba. Excelentísima Diputación Provincial de Ávila.

SACK, ROBERT D. (1986), Human territoriality. Its theory and history. Cambridge. Cambridge University Press.

SANZ-ZUASTI, J. Y VELASCO, T. (2000). Propuesta de la Consejería de Medio Ambiente para la declaración de Zonas de Especial Protección para las Aves (ZEPAs) en Castilla y León. Informe Final (Inédito). Consejería de Medio Ambiente. Junta de Castilla y León.

SOTELO NAVALPOTRO, J.A. (2012): Modelos de actuación contradictorios: Diez años después del prestige. $M+A, \mathrm{n}^{\circ} 12$, pp. 108-139.

SOTELO NAVALPOTRO, J.A. et alii (2012): Evaluation of tourism development in the National Parks of Spain, International Journal of Bussiness and Social Science, vol. $3, \mathrm{n}^{\circ} 14$, pp. 1-7.

SOTELO NAVALPOTRO, J.A. (2008): Riesgos naturales y tecnológicos en España, hoy. Observatorio Medioambiental, $\mathrm{n}^{\mathrm{o}}$ 11, pp. 9-12.

SOTELO NAVALPOTRO, J.A. (2008): Medio ambiente y desarrollo local, algo más que dos estereotipos. Observatorio Medioambiental, $\mathrm{n}^{\mathrm{o}}$ 11, pp. 77-105.

SOTELO NAVALPOTRO, J.A. (2007): Medio Ambiente, Desarrollo y Sostenibilidad: Modelos y Políticas de actuación contradictorias: entre lo global y lo local, Oxford University Press.

SOTELO NAVALPOTRO, J.A. (2000): "El Medio Ambiente en España, hoy", Instituto de Estudios Económicos.

SOTELO NAVALPOTRO, J.A. (1999): Modelos de Organización y desarrollo regional, Madrid, UCM/Oxford U.P, 165 págs.

SOTELO NAVALPOTRO, J.A. (1999): "Los Sistemas de Gestión Medioambiental: una aportación a la Ordenación del Territorio y del Medio Ambiente", Academia de las Ciencias, Homenaje a don Ángel Ramos, pp. 1485-1499.

SVAMPA, M (2009). La disputa por el desarrollo: territorio, movimientos de caracter socio-ambiental y discursos dominantes. Versión ampliada y actualizada del libro M. Svampa, Cambio de época. Movimientos sociales y poder político, Buenos Aires, Siglo XXI.

ZUKIN, S. (1989). Loft living. Culture and capital in urban change. New Brunswick, NJ: Rutgers University Press. 